\title{
Waste Management Problems in Jimma, Southern Ethiopia
}

\author{
*Filaba M. A.
}

\begin{abstract}
The major objective of the project was to design an approach to the problem of indiscriminate and nonclearance of generated wastes in the slums in Jimma town. The project, therefore, aimed to orient Jimma inhabitants to be hygienic, and to encourage the community to participate in setting up mitigating measures against environmental pollution through interface consultations using focused Group Discussions and In-depth Interviews. The scope of the project was limited to the more-slum wards in Jimma town. The findings were conspicuous, that speed of urbanization of Jimma town since ten years back became faster than the previous years, but a subsistence-urbanization. Subsistence urbanization is characterized by increase of the settlement in terms of scale and pace without corresponding increase in sanitation, infrastructures and without mitigating measures to address urban violence. The Wareda has been clearing the wastes where they placed the dustbins. It has also a number of town center cleaners. However, much of the cleaning of the streets and disposing of the wastes are individuals' efforts. The project encouraged more individual and group/community and professional effort in the cleaning of their nearest environments, and to earmark disposal units in the streets/wards. The Wareda was advised to increase distribution of dustbins and to embark on enlightenment. The generated animal and household wastes are good research materials for environmental scientist interested In studying what are generated, the chemical contents of the wastes and their impact on the immediate environment. The key concepts in this study are: Generation of domestic wastes and waste disposal; Urban pollution controls cum Waste Management.
\end{abstract}

\section{Introduction}

Scholarly studies (Filaba 2004) found high correlation between rapid urbanization of rural settlements and serious waste management problems. Further understanding of the ills of generated domestic, animal and urban wastes can be grasped beyond the purview of the generators of wastes in earlier studies conducted on urban pollutions (Brian, 1963; Hauser, 1963; Breese, 1969; Brian, 1973; Turner 1999; Filaba, 2004). Pollution as a result of generated and indiscriminate waste disposal is the biggest urban violence the newly developing towns and cities suffer from. Pollution simply means contamination of environment with materials that interfere with human health, the quality of life, or the natural functioning of ecosystems (living organisms and their physical surroundings). There are two main categories of polluting materials or pollutants. Biodegradable pollutants are materials, such as sewage, that rapidly decompose by natural processes. These pollutants become a problem when added to the environment faster than they can decompose. Nondegradable pollutants are materials that either do not decompose or decompose slowly in the natural environment. Once contamination occurs, it is difficult or impossible to remove these pollutants from the environment (Huang, 2000; Encarta, 2003).

Urban environmental pollutions are caused by human activities through generation and disposal of wastes. It has been established that the nondegradable compounds such as dichlorodiphenyltrichloroethane (DDT), dioxins, polychlorinated biphenyls (PCBs), and radioactive materials can reach dangerous levels of accumulation as they are passed up the food chain into the bodies of larger animals and humans. For example, molecules of toxic compounds may collect on the surface of aquatic plants without doing much damage to the plants. A small fish that grazes on these plants accumulates a high concentration of the toxin. Larger fish or other carnivores that eat the small fish will accumulate even greater, and possibly life-threatening, concentrations of the compound. This process is known as bioaccumulation. Because humans are at the top of the food chain, they are particularly vulnerable to the effects of nondegradable pollutants. This was clearly illustrated in the 1950s and 1960s when residents living near Minamata Bay, Japan, developed nervous disorders, tremors and paralysis in a mysterious epidemic. More than 400 people died before authorities discovered that a local industry had released mercury into Minamata Bay (Encarta 2007).

*Faculty of Education, Jimma University, P. O. Box 378, Jimma, Ethiopia mfilaba@yahoo.co.uk 
This highly toxic element was accumulated in the bodies of local fish and eventually in the bodies of people who consumed the fish. More recent research has revealed that many chemical pollutants, such as DDT and PCBs, mimic sex hormones and interfere with the human body's reproductive and developmental functions. These substances are known as endocrine disrupters. Pollution also has a dramatic effect on natural resources and thereby impairing them. Another major effect of pollution is the tremendous cost of pollution cleanup and prevention. The global effort to control emissions of carbon dioxide, a gas produced from the combustion of fossil fuels such as coal or oil, or of other organic materials like wood is the talk of the year 2007, and it is found costly. In addition to its effects on the economy, health and natural resources, pollution has social implications. Research has shown that low-income populations and minorities do not receive the same protection from environmental contamination as do higher-income communities. Toxic waste incinerators, chemical plants, and solid waste dumps are often located in low-income communities because of a lack of organized, informed community involvement in municipal decision-making processes (Leycun, 2001; Obiri, 2007; Kolawole, 2007).

Urbanization of the Federal Capital Territory Abuja, as with many other towns in Africa (Olowu, 1995; and Townsend,1962; Abiodun, 1998:), was partly characterized by evolution of Squatters Settlements which depicted the urban poor living below poverty line and could not efficiently manage their disposed wastes and with inadequate government facilities. And the inhabitants are "severely poor" as they cannot afford the necessities of life. Abiodun noted that the urban poor live in areas with bad environmental conditions without basic services due to the breakdown of urban infrastructure and poor health (Abiodun, 1998). The phenomenal comparatively more speedy urbanization process in the developing world rapidly engulfing its rural communities has inherent human consequences: "giving rise to shanty township and slums with poor sanitation fostering the spread of infectious diseases. Further overcrowding causes health hazards like tension, anxiety, neurosis and social adversities like family trouble, divorce and crime" ( Singha, 1976).

Some scholars found that development and urbanization is more rapid in the developing countries than was the case with the advanced world centuries ago. In the developing countries urbanization engulfs people with lowest levels of life expectancy at birth, poorest nutrition levels, lowest energy (electricity) consumption level and lowest levels of education and compounding problems of waste management as the governments are in a hurry (Brian, 1973:78), and the consequence is filthy periphery of cities, helpless Displaced Persons, perpetuated urban violence, squalor and "the global spread of slum from ranchos of Caracas and favellas of Rio, to the gececondu of Ankara, to the bidonville and 'tin can cities' that infest the metropolitan centres of every developing country from Cairo to Manila (Lerner, 1967).

Similar development characterizes Jimma town located some $400 \mathrm{~km}$ south of Addis Ababa under Orimia Region. The evolution of the settlement and gradual urbanization in time perspective is elaborately discussed in the works of Huntingford (1955), Lewis (1965), Abir (1966) and Graham (2007). Jimma town is about $100 \mathrm{~km}^{2}$ and densely populated as a result of rural-urban migration, schools and the economic activities. In the recent times, there is a correlation between the urbanization of Jimma town and increasing waste generation and problems of disposal. The effort of the Woreda and individuals is overshadowed by the rapid growth of the town. The growth of institutions of learning particularly Jimma University is one of the major accelerators of Jimma urbanization. Other factors of the urbanization of Jimma are natural increase of population, rural-urban migration, the growth and activities of Churches, government policies of infrastructural development, inputs of NGOs, marketing and transportation, to mention the major ones only. The growth of the town is symmetrical to the expansion of the University as those staff members who cannot be accommodated in the University quarters buy plots close-by and developing them. Closely linked to the above, some wellto-do persons are raising structures in order to let to students. All the junior categories of workers reside outside the university. Most of the retirees also bought plots and live in 
Jimma now as their permanent home. Many households comprise of both primary and secondary families, as many of the workers of Jimma and some few self-employed are renters. This is partly a response to the large admission policy without commensurate hostels to accommodate the students, and partly due to the in-coming of investors.

The rapid growth of Jimma town and the presence of migrants attract marketers and professionals of all sorts that generate both domestic and commercial wastes. For instance, there are computer operators, salons sagurbet, mechanics, cobblers - listro, and can workers, recycling used shoes and utensils - arogetara, that leave behind the waste products. There are now many cart commuters - gari, with large number of horses and donkeys that draw the carts and the animals (feres- horse, wusha-donkey, lam - cow) drop their shits everywhere, while their remnant feeds are improperly disposed. In a similar manner, the many groceries, chat leaf shops and wood dealers, sugar-cane dealers, maize roasters, etc generate wastes. Many carpentry and iron bending workshops are evolving along the roadsides dropping the rough scraps. $40 \%$ of the households in the slums have gar, and only $2 \%$ and $10 \%$ of households have cows and goats/sheep respectively. $60 \%$ and $2 \%$ households have dogs and cats respectively.

The project was an action plan submitted to Jimma University Publication and Research Extension for consideration. Its general objectives were to: encourage community participation on sanitation; enlighten beneficiary community on existing environmental protection laws; and to encourage investment on waste recycling and consultation on waste disposal and management. The specific objectives were: to inculcate the habit of cleanliness; reduce indiscriminate waste disposal in order to minimize the pollution of surface and ground water; and to ear-mark waste-disposal points.

Three hypothesis were postulated: "Awareness program on the dangers posed by indiscriminate waste disposal can influence hygienic behaviour"; "Clearly ear-marked waste-disposal points can bring about household and street sanitation with corresponding increase in the beauty of the town"; and "There is high correlation between indiscriminate waste disposal and urban epidemics." As the project was about to end, these hypothesis were tested during the monitoring and feed-back session. The first two hypotheses appeared like a maxim in Kochi, Agric and Addisu-gabia wards where the sensitization and earmarking of disposal units truly led to cleaner streets. A longer period needed for testing the third hypothesis. But the testimonies of the respondents seem self conclusive that the prevalence of vectors has to do with poor cleanliness. It was debated that there are more endemics in rural areas that are literally 'less' polluted than the towns. This might be as a result of accessible clinics in the towns resulting in addressing diseases vis a vis the insulated villages.

The significance of this type of project is obvious. It would encourage participatory environmental management program with the view to inculcate the attitude of hygiene. The Jimma indigenes will also become aware of the environmental protection laws and the need to involve the community in the effort, as the government is saddled with other equally urgent responsibilities. The program has the additional advantage of influencing the students and tourists to replicate the process in their other communities. The desired hygiene attitude can be re-enforced with posters, sign boards and the media. The programme will enable other researchers to modify the proposal with the view to replicate it on other communities.

The major research questions were: Where do the house-holds dispose off their rubbish? What are the perceived health hazards associated with indiscriminate waste disposal? What can the ward/community put in place to enforce environmental protection laws and also encourage hygienic habit of individuals and of the whole ward?

\section{Methodology}

First of all there were both purposive sampling of the more sub-urban areas of Jimma. Then there was random sampling of the wards/zones where the survey was conducted. There was cluster zoning of wards for In-Depth Interviews (IDIs) and Focused Group Discussions (FGDs) with household heads mostly men of ages 30 to 50 , and professionals, women inclusive as they operated the salons and manna coffee, particularly around the koshaka, which were conducted between September 2007 and 
January 2008 in each of the wards and groups as in the Table 1.

The survey took one year as permission and selection and scheduling of FGDs took time while some respondents were quit reluctant. The survey started with trail of the garbage (koshasha) sites and solicitation for permission to embark on the project up to the data reporting stage, was spread across eight months. There was observation trek to identify the nature and contents of both the organic and inorganic disposals and their generators as sample sites and index/catalogue/plates.

The topics that the responding participants were asked to comment on were: to identify where the households, coffee shops, wood dealers, traders, etc in the ward dispose their rubbish/refuse; to mention the perceived environmental pollution in the ward (indiscriminate waste disposal; chemicals/salination; noise; smokes; gutters; smells, animal shits and feeds, scraps, domestic rubbish, etc) and who are the generators/emitters of each type; to mention the various sources of water for domestic work in the ward and comment on whether each source is good or bad for drinking; to tell how each household dispose used water; say the types of latrines in their houses; and to discuss the perceived effects/threats of the pollutions.

They were also to reveal any earlier complaint/comment/response by individuals or groups on the effects of the pollution; and what channels used for complaining and response by the emitters; and to mention the action like community association if any by the community/ward or individual to address the issue in the ward. They were also asked to comment on the government effort to address the environmental pollution problem in the ward and give their suggestions on how to address the problem and what assistance they need to address the problem. Suggestions like the need to employ someone or group and to pay them token fee for refuse collection by their houses/wards, and the need to obey the government's environmental sanitation/protection laws known to the community are also mentioned.

\section{Resuts and Discussion}

These were the identified generators of wastes in the raking order of occurrence in the FGDs and IDIs: gari left-out feeds and dungs, market, manna khat, manna coffee, manna beer, mechanics, wood dealers, grinding mills, salons, households, abattoirs, and nonchalant attitudes of individuals.

The commonest wastes observed in the koshasha were: khat remnants; home rubbish and food remnants; polithyne bags (pesta); torn shoes and clothes, broken bottles/plates, horse dung; carcass; pieces of iron implements and wood. Some of the koshasha contained bagged human faeces. Around makerto, the dustbins contained rotten food items, pesta, papers, grain and flour remnants from grinding mills, liquid elements, batteries, torn clothes and so on. Around Kullober and Agip wards were abandoned car scraps, iron implements and wood, in addition to other rubbish. Sugar-cane waste were often seen indiscriminately dropped in all the wards.

Discussants attributed the growth of some garbage dumps that expanded and blocked some roads and drainages - boyie to lack of earmarked spaces for koshasha metaya. Others identified the culture of throwing away carcasses and bones, legs and heads of animals killed on the street for hyenas and dogs to feed on, which attract hyenas to patronise the streets at nights.

Poor drainage was mentioned in all the FGDs and IDIs, as most parts of Jimma are traditional without planning. In fact, as a traditional society, the passages are not protected, and are easily blocked with "Chika" whenever it rains. But thanks be to the World Bank Project now helps resuscitating the streets of Jimma.

It was revealed that many of the bus owners and mechanics dispose of wasteengine oil in the gutters, which makes the place eye-sore. Similarly, the sugarcane and wood dealers leave the roughs by the street and would be dispersed into the drains and cause blockades. Animals -mainly the cows and horses for gari graze freely dropping their shits along the way, and must be concomitants of intestinal worms. In deed, one can watch millions of red-worms in both the stagnant and running gutters. This is believed to also percolate down the ground and contaminate the underground water. It was also mentioned that the machine grinding mills around the makerto dispose chaffs on the street. Remnants of food and seeds from fruits and maize are left on the roadside. The main makerto is not 
drained and cramped that when it rains the odour and the chika are terrible.

Informants noted that some individuals burn their animal dung outside and the smoke disturb the neighbourhood. Some dustbins are managed by burning, and the burning polythene/pesta bags, rubbers and stool smells are worrisome to the helpless neighbourhood.

Another very serious problem is that Streets and Houses are not named or numbered that visitors find it difficult to trace points. Few discussants identified the problem of the behaviour to block passages as neighbours take all their plots for building and not leaving any space for rain and gutter water to pass through. Even in the new areas, the streets are yet to be drained.

It was estimated that only about $60 \%$ of the owners of animals and pets patronise the Vetinary in AGIP ward and the various animal clinics at frequent intervals. The soil texture of Jimma is a marshy and muddy one - major characteristic of the Rift Valley in which Jimma is located. All settlements with these characteristics necessarily face sanitary problems as the mud - chika - forms on the road and become eye-sore and uncomfortable trapping. The chika contaminated with animal shits and indiscriminate waste disposal attract flies and other vectors, and therefore infest the inhabitants with worms of all sorts. Indeed, informants identified the prevalence of rats and small cockroaches in the slum areas. They also mentioned the chronic problems of intestinal worms, athlete feet, skin problems and other diseases attributed to polluted water.

The sanitary implications are obvious as the dirt spots are reservoirs of mosquitoes, cockroaches, rats, bed-bugs and other vectors with the potential concomitant effects of endemic malaria, typhoid and intestinal related diseases. Except the newly modern houses that have flush toilets, most houses in the slums have shallow pit toilets; some of them share the toilets, while some do not have any. Estimates of discussants were that $70 \%$ of houses in the slum areas have pit toilets. $10 \%$ of them share the pit toilets, $15 \%$ do not have, and. $5 \%$ of the houses in the slum areas have flush toilets. About $10 \%$ households have no bathrooms and do it in rubber basins and dispose the water on the road.

On the attempt of the government, informants made it known that the major streets have been supplied with the rubbish disposal units - koshaka-metaya - by the Oromia Wareda, while many of the slums areas do not have them. Many popular and crowded streets still suffer from insufficient waste-disposal units, and there is infrequent clearing of the dust-bins, which result in accumulation and rotting of the wastes attracting flies and emitting terrible odour. Most traditional resident wards, streets craft industries and markets of Jimma town are eyesores as there is poor drainage and insufficient earmarked koshasha metaya. These unhealthy conditions are potent future epidemic reservoirs. The available epidemiological records at the clinics attest to the persistence of vectors and sanitary concomitant diseases. The perceived implication is that the health of the University community and of the inhabitants is at stake.

\section{Conclusion}

Combinations of factors are responsible for the rapidly urbanizing of Jimma and educational institutions and Churches are very glaring (Seifu, 2006). There has been gradual growth of the town in terms of expansion since the $19^{\text {th }}$ century. In the recent years, the rapid urbanization is attributed to government policies, NGOs, rural-urban migrations, activities of the Churches and Muslims, and marketing. The effort of the Wareda in the areas of supplying the dustbins and collection of the wastes has been the dominant method of keeping Jimma clean. But the population is too large for the Wareda. There are individual and group attempts to keep the environment clean by burning the wastes, or contracting some individuals and gari to collect and dispose the wastes. The disposal units are too few and some of them are far away from the slum areas, and thus they simply dispose them in the ditches, gutters and road-sides. Garbage heaps can be sighted in almost every ward.

Informants related that waste disposal is a problem and the garbage heaps are sources of vectors and diseases over which they have no control. In our study, the households and the wood and sugar-cane dealers, grinding mills and mechanics and carpenters are pointsource pollutions. Non-point-source pollution comes from dispersed or uncontained sources, such as contaminated water runoff from, broken pipes, running gutters from numerous households, automobile emissions and the 
roamin animals. The effects of these pollutants may be immediate or delayed. Primary effects of pollution occur immediately after contamination occurs, such as the death of a neglected animal outside. The effect of used engine oil and batteries gradually accumulated in their bodies, may be delayed but poisonous.

Generation and indiscriminate waste disposal is a pandemic problematic, with unwanted solid materials such as garbage, paper, plastics and other synthetic materials, metals, and wood, in billions of tons of solid waste thrown out daily. These synthetic materials take longer to decompose than the primarily biodegradable waste materials and thus one of the major problems in the fast developing towns in the developing countries (Filaba, 2004).

Based on the gravity of noted waste management problems in Jimma town, there is the need to intensify sensitization and mobilization for supporting the government effort in managing the disposed wastes. The Woreda should make regular collection of filled koshashas and as well enforce the environmental protection laws.

It is suggested that the Oromia Region and the various Woredas should develop a Matrix of Environmental Pollution and Control for the emerging towns, showing at a glance the nature of the environmental pollution, the emitters, their effects, suggested mitigating measures to put in place, etc. to be submitted to community leaders and the policy makers and implementers.

In view of the fact that Jimma is a resident for both the workers and students, there is the urgent need for orienting the community to be sanitation conscious, and participatory in keeping the immediate environment clean. The community service of the Jimma University by mounting the sensitization program is therefore a desideratum. Indeed, Jimma University has been rated as the best environment clean-wise in the town and of course in the country. This should be extended to its host community too, by fulfilling its community service and encouraging/sponsoring community-based projects that organise community participatory environment cleaning programme.

Similarly, the community leaders should form ward associations for keeping their wards clean. The role of the government and the media, as well as NGO (Jimma has Ethiopia For Change EFC) in forms of public sensitization with production and distribution of posters, more koshaha, signboards, etc, to re-enforce the desired change in the behaviour of waste disposal and management, are needed. There is also the need for miniworkshops on waste management and recycling as such will have additional advantage of creating job opportunities. The Wareda could draw a matrix of waste generation, effects and management in Jimma town, which can be replicated in other towns.

There is also the urgent need for the Wareda to name and create signboards for the major Streets and Wards in the Town. There is also the need for more systematic investigation and laboratory experimentation of the nature and impact of the generated wastes in the town, by carrying out Laboratory analysis of the disposed wastes in order to know their toxidity and diseases contents and impact on the immediate environment.

All the literature referred to in the course of this project had suggested various methods of waste management but principally waste recycling and disposal, which Ethiopian government can borrow. Some of them suggested the use of incinerators; burying/landfills system; composting method; organized waste-pickers comb streets and dumps for items such as plastics, for re-use or resold; recycling programs; reduction of waste generation; treatment of very hazardous solid, liquid, or gas and radioactive waste and so on. 


\section{References}

Abir M., (1966) "Jimma Abba Jifar: An

Oromo Monarchy Ethiopia 1830-

1932."The Journal of African History, Vol. 7,

No. 3 pp. 516-519

Albert O. et al, (1992) Urban Management and Urban Violence in Africa. IFRA

Ibadan, (2 vol.)

Abiodun, J.O. (Mrs) (1998), J. O., "Environment, Poverty and Sustainable Development in Nigerian Cities." The Nigerian Social Scientist, Vol.1, No1, news Letter of Social Science Council of Nigeria, September.

Breese G., (1966) Urbanization in Newly Developing Countries. Printice Hall Int. Inc.Breese G. ed, (1966) The City in Newly Developing Countries: Reading on Urbanism and Urbanization. Prentice Hall.

Brian, L. B. ed, (1973) Human

Consequences of Urbanization.MacMillan. Filaba, M.A., (2004) “A History of Karu with Specific Reference to the Consequences of the Rapid Urbanization Process of the Federal Capital City: 19762002" Ph. D. thesis (unpub.) A.B.U. Zaria. Clement J. P. (2006) "Environmental Management" Microsoft $₫$ Encarta ${ }^{\circledR}$ 2006

Microsoft Corporation.

Graham J. "the Cities of Ethiopia." jgraham@telecom.net.et, accessed in January 2007.

Hauser P., (1963) "The Social, Economic andTechnological Problems of Rapid Urbanization". B. F. Hoverlitz \& W. E. Moore, eds., Industrialization and society. Paris,UNESCO.

Huntingford G.W.B., (1955) The Galla of Ethiopia; the Kingdoms of Kafa and Janjero. London: International African Institute.

Jerry Y.C. Huang, (2000)

Air Pollution; Environment; Sewage

Disposal; Water Pollution, New York.
Kolawole O. M. et al (2007) Studies on the Efficacy of Bridelia Ferruguinea Benth Bark Extract for Domestic Wastewater Treatment." Bulletin of the Chemical Society of Ethiopia. Vol.21 No.2 Aug. 2007. CSE Addis Ababa.

http://www.ingentaconnect.com Lewis H. A., (1965) A Galla Monarchy: Jimma Abba Jifar Ethiopia, 1830-1932. Madison: University of Wisconsin Press. Lerner D., (1967) "Comparative Analysis of Processes of Modernization." In Horace Miner, ed., The City in Modern Africa. Pall, London,

Leykun J. (2001) "Soil Transmitted Helminth Infections and Scistosomiasis Mansoni in Chilga District. Northwest Ethiopia." Ethiopian Journal of Health Sciences July 2001 Vol.11

No.2 Jimma University. Microsoft @ Encarta ® Encyclopedia, (2003)

"Solid and Liquid Waste Disposals and Pollution" (C) 1993-2002 Microsoft Corporation. Ministry Of Works and Environment, (2003) Environmental Protection, Addis Ababa. Obiri S. et al (2007) "Determination of Free Cyanide and Total Cyanide Concentrations in Surface and Underground Waters in Bogosso and Surrounding Areas in Ghana." Bulletin of the Chemical Society of Ethiopia. Vol.21 No.2 Aug. 2007. CSE Addis Ababa. http://www.ingentaconnect.com Onibokun, A. et al (1995) Government and Urban Poverty in Anglophone West Africa. Center for African Settlement Studies and Development (CASSAD), Monograph Series 4.

Sifu Y. (2006), “A Historical Survey of Modern Education in Jimma Town 19301990" Jimma University, Unpubl.

Singha P., (1976) Introduction Text on Demography. Gas. Corp. Ltd, Zaria, 1976. The World Bank, (1966) Poverty Reduction Handbook. Washington D.C. 317.

World Bank (1990) Towards the Development of an Environmental Action Plan for Nigeria. West African Dept. 165. World Bank 1995) Nigerian Poverty Assessment. Population. and Human Resource. Div. Draft 
World Bank (1996) Nigerian Prospect for Development, West Central Africa Dept., country operation Division Drafts, 165, Townsend, P. (1962) The Meaning of Poverty." The British Journal of Sociology, Vol. 13, pp. $210-213$.
Turner J. F. C., (1969) "Uncontrolled Urban Settlement: Problems and Policies." in G. Breese, ed. (1969), The City in Newly Developing Countries. Prentice Hall Inc, N.J. 1969, pp. $471-506$.

Wikipedia, the free encyclopedia (2007)

"Jimma Abba Jifar."

WWW:http: Environmental Impact Assessment Lectures.com/. Internet accessed 2007.

Table 1- Distribution of FGD and IDI in the Study Area

\begin{tabular}{|l|l|}
\hline Focused Group Discussions (FGD) and In-depth Interviews (IDI) Zones/Schedule \\
\hline Mazorin ward 2 FGDs; 1 IDI & Saroa (Agric.) ward 2 FGDs; 2 IDIs \\
\hline Kochi ward 2 FGDs; 2 IDIs & Mentina ward 3 IDIs \\
\hline Dippo ward 1 FGD; 1 IDI & Hemata 1 FGD; 1IDI \\
\hline AGIP ward 1FGD; 3 IDIs & Abotoir 4 IDIs \\
\hline $\begin{array}{l}\text { Addisu-gabia ward 4IDI and Blocks } \\
\text { dealers) }\end{array}$ & Shoaber (Central hotel) Ward 3 IDI \\
\hline Michael church ward 2 FGDs & Wood deports in Jimma 6 IDIs \\
\hline Kullober ward 4 IDI & Salon Operators in Jimma 5 IDIs \\
\hline Mdnnare ward 2 FGDs, 2 IDI & $\begin{array}{l}\text { Mechanic and Carpentry Workshops in Jimma 8 } \\
\text { IDIs }\end{array}$ \\
\hline $\begin{array}{l}\text { Merkita 6 IDIs (grinding mills; arable } \\
\text { dealers; pottery) }\end{array}$ & $\begin{array}{l}\text { Community leaders, Local Government and } \\
\text { politicians of Jimma; Ethiopia For change (FCE) } \\
\text { NGO) 6 IDIs }\end{array}$ \\
\hline
\end{tabular}

